\title{
DICER1 hotspot mutations in ovarian gynandroblastoma
}

Running title: DICER1 in gynandroblastoma

Yemin Wang ${ }^{1,2, \#}$, Anthony N. Karnezis ${ }^{1,2, \#, ~ J a m i e ~ M a g r i l l ~}{ }^{2}$, Basile Tessier-Cloutier ${ }^{1,2,3}$, Amy

Lum $^{2}$, Janine Senz ${ }^{1,2}$, C. Blake Gilks ${ }^{1}$, W. Glenn McCluggage ${ }^{4}$, David G. Huntsman ${ }^{1,2,5}$,

Friedrich Kommoss ${ }^{6}$

${ }^{1}$ Department of Pathology and Laboratory Medicine, University of British Columbia, Vancouver

BC, Canada

${ }^{2}$ Department of Molecular Oncology, British Columbia Cancer Research Centre, Vancouver, BC,

Canada

${ }^{3}$ Molecular Oncologic Pathology Fellowship Program, Terry Fox Research Institute, Vancouver,

BC, Canada

${ }^{4}$ Department of Pathology, Belfast Health and Social Care Trust, Belfast, Northern Ireland, UK

${ }^{5}$ Department of Obstetrics and Gynaecology, University of British Columbia, Vancouver, BC,

Canada

${ }^{6}$ Institute of Pathology, Medizin Campus Bodensee, Friedrichshafen, Germany

\# These authors contributed equally to this work.

\section{*Correspondence to:}

Friedrich Kommoss, M.D. 
Institute of Pathology

Roentgenstr. 2

88048 Friedrichshafen, Germany

Phone: +49 7541 9673001; Fax: +49 75419673003

Email: friedrich.kommoss@pathologie-fn.de

David Huntsman, MD, FRCPC, FCCMG

Canada Research Chair in Molecular and Genomic Pathology

Dr. Chew Wei Memorial Professor of Gynaecologic Oncology, University of British Columbia

Professor, Departments of Pathology and Laboratory Medicine and Obstetrics and Gynaecology, UBC

Director of OVCARE, Vancouver General Hospital, BC Cancer Agency and UBC

Distinguished Scientist, Department of Molecular Oncology, BC Cancer Agency Cancer Research

Centre

675 West 10th Avenue, Vancouver, BC V5Z 1L3

Phone: +1-604-675-8211

Email: dhuntsma@,bccancer.bc.ca

Conflict of interest: None of the authors report any conflicts of interest.

Word Count for main text (limit 2500): 2499 


\begin{abstract}
AIMS: Gynandroblastoma is a rare ovarian sex cord-stromal tumor characterized by the presence of both male (Sertoli and/or Leydig cells) and female (granulosa cells) components. We investigated the mutational status of DICER1, FOXL2 and $A K T 1$ genes at hotspot regions that are known to be the key driving events in the development of Sertoli-Leydig cell tumor (SLCT), adult granulosa cell tumor (aGCT) and juvenile granulosa cell tumor (jGCT), respectively, to gain insights into the molecular pathogenesis of gynandroblastoma.
\end{abstract}

METHODS AND RESULTS: Sixteen cases of gynandroblastoma were studied. All contained SLCT or Sertoli cell tumor components. aGCT and jGCT components were identified in seven and ten cases, respectively, with one presenting both components. Heterozygous hotspot mutations in the RNase IIIb domain of DICERI were discovered in three cases including one case with heterologous mucinous elements, all of which were composed of moderately or poorly differentiated SLCT and jGCT components, and harbored the mutations in both histologic components. None of the sixteen cases displayed mutations at the p.C134W $(c .402 C \rightarrow G)$ of FOXL2 or within the pleckstrin-homology domain of AKT1. All cases showed FOXL2 immunostaining in both male and female components.

CONCLUSION: DICERl hotspot mutation is the key-driving event in a subset of gynandroblastomas containing components of SLCT and jGCT. Gynandroblastomas composed of SLCT and jGCT may represent the morphological variants of SLCT. The molecular basis of gynandroblastoma containing a component of aGCT is different from pure aGCT.

Keywords: gynandroblastoma, Sertoli-Leydig cell tumour, granulosa cell tumour, DICER1, FOXL2, AKT1 


\section{INTRODUCTION}

Gynandroblastoma is a rare mixed sex cord-stromal tumor characterized by the presence of both male (Sertoli and/or Leydig cells) and female (granulosa cells) components ${ }^{1}$. It occurs in the ovary or the testis, although only very few testicular examples have been reported ${ }^{2}$. The female components of ovarian gynandroblastoma are granulosa cell tumor (GCT), of either juvenile (jGCT) or adult type (aGCT), while the male elements consist of Sertoli cell tumor (SCT) or Sertoli-Leydig cell tumor (SLCT) ${ }^{3}$. Clinically, gynandroblastomas may cause virilisation as a result of endocrine androgen secretion by tumors ${ }^{4}$, but estrogenic manifestations have also been reported $^{5,6}$.

Although patients are usually diagnosed at stage I, some ovarian gynandroblastomas have metastasized, so they are considered to be of low malignant potential ${ }^{7}$. Therefore, patients with gynandroblastoma sometimes receive chemotherapy with carboplatin and paclitaxel on the basis of histological similarity of the tumor to GCT and SLCT ${ }^{8}$; however, the rationale for this clinical practice is lacking as it is unclear whether gynandroblastoma is pathogenetically related to GCT or SLCT. Recent studies have shown that about $95 \%$ of aGCTs harbour the p.C134W mutation in FOXL2 ${ }^{9-13}$, while in-frame duplications affecting the pleckstrin-homology (PH) domain of $A K T 1$ and/or activating $A K T 1$ mutations were identified in $87.5 \%(14 / 16)$ of jGCTs in girls under 15 years old ${ }^{14}$. Furthermore, about half or more of ovarian SLCTs harbour mutations in the RNase IIIb domain of DICER ${ }^{15-18}$ that skew the maturation of microRNAs ${ }^{16,19}$. No FOXL2 p.C134W mutation was identified in seven ovarian gynandroblastomas analyzed by Oparka et al ${ }^{20}$. In contrast, Conlon et al analyzed 5 gynandroblastomas and discovered mutually exclusive $F O X L 2$ p.C134W mutations and DICER1 mutations in two and three cases, respectively ${ }^{18}$. The 
discrepancy between these two studies highlights the need to investigate the mutational status of DICER1 and FOXL2 in a centrally reviewed cohort of cases diagnosed as gynandroblastoma.

Although commonly used by pathologists for a neoplasm comprised of at least $10 \%$ of both male and female sex cord elements, the term gynandroblastoma is no longer used in the 2014 World Health Organization (WHO) Classification of Tumours of the Female Reproductive Organs ${ }^{21}$. The rationale to remove it from the classification is unclear and there is no category that encompasses tumors composed of both male and female sex cord elements. In order to address whether ovarian gynandroblastoma shares key genomic features with SLCT or GCT, we performed mutational analysis of FOXL2, DICER1 and $A K T 1$ and analyzed FOXL2 protein expression in a cohort of 16 ovarian gynandroblastomas.

\section{MATERIALS AND METHODS}

\section{Patients and samples}

Sixteen ovarian gynandroblastomas were obtained from archives of three authors (W.G.M., F.K. and C.B.G.). Approval for tissue use was gained from local ethical committees with research ethics board-approved protocols for mutation analysis (H02-01411, renewed May 29, 2017) and immunohistochemical (IHC) analysis (H02-61375, renewed March 30, 2017) being obtained from University of British Columbia. Upon histological review by two gynecologic pathologists (F.K. and A.N.K.), all the cases fulfilled the diagnostic criteria for a diagnosis of gynandroblastoma.

\section{DNA extraction and microdissection}


Whole scrolls of tumor blocks were used for DNA extraction. To separately isolate tumor from the different histologic components, tissue macrodissection was manually performed on unstained slides based on an adjacent H\&E-stained section marked by a pathologist. Samples were deparaffinized and genomic DNA was purified using QIAamp DNA FFPE Tissue Kit (Qiagen) following the manufacturer's protocol.

\section{Taqman FOXL2 allelic discrimination assay}

TaqMan real-time PCR based allelic discrimination assay was performed as described previously

${ }^{22}$ to genotype the FOXL2 $c .402 C>G$ mutation using primers: 5'-GCGCAAGGGCAACTACTG3' (forward) and 5'-CGGTAGTTGCCCTTCTCGAA-3' (reverse), along with wild type specific probe (5'-FAM dye- CATGTCTTCCCAGGCCG-NFQ (non-fluorescent quencher)) and mutation specific probe (5'-VIC dye-CATGTCTTCGCAGGCCG-NFQ). Reactions were performed in a 7900HT Fast Real-Time PCR System (Applied Biosystems) with DNA from a molecularly diagnosed aGCT sample ${ }^{9}$ as a positive control.

\section{DICER1 mutation analysis by MiSeq}

The genomic sequence of DICERI spanning RNase IIIb domain hotspot mutations was amplified by PCR reaction with 4 primer sets listed below using Platinum PCR Supermix High Fidelity kit (ThermoFisher) according to manufacture's instruction. All 4 amplicons of each sample were pooled, diluted and barcoded by PCR with FastStart Taq DNA Polymerase (Roche). Two independent libraries from each sample were generated, pooled, and purified with Agencourt AMPure XP (Beckman Coulter). The library was then diluted to 8pM and loaded into Illumina Miseq Reagent Kit V2 (300-cycle). The vcf files generated by Illumina Miseq Reporter were 
used to identify mutations. All mutations were either present in both libraries or present in at least one library and validated by Sanger sequencing. The primers used for sequencing included: 1) DICER1_P2_1F (5'-ACACTGACGACATGGTTCTACAACAAGCTTACGGTTCCACTTC-3') and DICER1_P2_1R (5'-

TACGGTAGCAGAGACTTGGTCTGCGATGCAAAGATGGTGTTG-3') to analyze E1705/D1709 sites; 2) DICER1_P2_2F (5'-

ACACTGACGACATGGTTCTACAAAATACAAATCTTCTTCGGATTT GGG-3’) and DICER1_P2_2R (5'-TACGGTAGCAGAGACTTGGTCTCGGGTCTTCATAAAGGTGCTT-3') to analyze E1705/D1709 sites; 3) DICER1_TM_1F (5'-

ACACTGACGACATGGTTCTACAGGAGATCTGAGGAGGATGAAGA-3') and DICER1_TM_1R (5'-

TACGGTAGCAGAGACTTGGTCTTCTAAAGGGAGCCAACAATACCT-3') to analyze D1810/E1813 sites; and 4) DICER1_TM_2F (5'-

ACACTGACGACATGGTTCTACAAGAAACTACATCTGTGGACTGCC-3') and DICER1_TM_2R (5'-

TACGGTAGCAGAGACTTGGTCTTCTCCAGTGACATCCCACTATC-3') to analyze D1810/E1813 sites.

\section{Sanger Sequencing}

M13 tagged PCR primer sets were designed to amplify regions of the RNase IIIb domain of DICER1 or the pleckstrin-homology domain of $A K T 1$. Initial PCR amplification was done with Platinum Taq DNA polymerase high fidelity (Life Sciences). The primers included Dicer1_P2 and Dicer1_TM primer sets described above that sequenced E1705/D1709 sites and 
D1810/E1813 sites, respectively, and AKT1 primer set: 5'-GGCCCAACACCTTCATCA3'(sense) and 5'- TCCTCAGGAGTCTCCACAT-3'(anti-sense). To identify samples with duplications of the AKT1 PH domain, PCR products of AKT1 amplicons were resolved by gel electrophoresis with a case of jGCT harbouring duplication of the AKT1 PH domain as a positive control. PCR products of PCR amplicons were purified using EXoSAP-IT (USB products Affymetrix). Seqeuncing reactions were done in both forward and reverse directions using M13 primers and the ABI BigDYe terminatore v3.1 cycle sequencing kit (Applied Biosystems). Amplified products were then sequenced using an ABI Prism 3130x Genetic Analyzer by Source Bioscience.

\section{Immunohistochemistry (IHC)}

FOXL2 IHC was performed using primary goat polyclonal FOXL2 antiserum (1:200; Imgenex) and a secondary antibody (1:300; unconjugated rabbit anti-goat, Jackson ImmunoResearch Labs). Assessment of FOXL2 IHC was performed by a gynecologic pathologist (A.N.K.). Any nuclear staining was considered positive.

\section{Statistical analysis}

Student's $t$-test was used to evaluate significant differences between two groups. Fisher's exact test was used in the analysis of contingency tables. A $p$-value $<0.05$ was considered significant.

\section{RESULTS}

Characteristics of ovarian gynandroblastomas 
The clinical information of all 16 ovarian gynandroblastoma patients is summarized in Table $\mathbf{1}$. The median age of all patients was 24.5 years (range 14-80). Histological review showed that $94 \%(15 / 16)$ of cases contained SLCT as their male components, including two cases that also had a component of sex cord-stromal tumour, unclassified (case 5) or SCT (case 9). The remaining one case only had SCT as the male component (case 10). Among the 15 cases with a SLCT component, $47 \%$ (7/15) of the cases had well differentiated SLCT, whereas the other eight cases contained SLCT of moderate or poor differentiation, of which one displayed heterologous intestinal-type mucinous glands (case 4, Figure 1). Regarding female components, $62.5 \%$ $(10 / 16)$ and $43.8 \%(7 / 16)$ of the cases contained variable amounts of jGCT or aGCT components, respectively, including a single tumor that had an aGCT component with microscopic foci of jGCT (case 9). The median age of patients with gynandroblastoma with either a jGCT or aGCT component were 23 and 24.5 years old, respectively. Representative hematoxylin and eosin images are shown in Figure 1 (SLCT/jGCT, case 4) and Figure 2 (SLCT/aGCT, case 8).

\section{Mutational analysis in gynandroblastoma}

Targeted next generation sequencing of genomic sequence spanning somatic DICERI hotspot mutations within RNase IIIb domain showed that 19\% (3/16) of the cases had heterozygous DICERI mutations at one of the key metal binding sites, comprising p.E1705V, p.E1813K and p.D1810H (Table 2). An additional mutation, p.W1831X, was identified along with the DICERI p.E1705V hotspot mutation in case 3, but its impact on DICER1 function is unclear. These mutations were further validated by Sanger sequencing.

DICER 1 mutation tended to occur in younger patients with a median age at diagnosis of 20 years (range 15-26) compared to 26.5 years for gynandroblastomas without DICER1 mutation 
(range 14-80) (Figure 3A, $P=0.25$ ). All three gynandroblastomas with DICER1 mutations contained moderately or poorly differentiated SLCT as male components, including one case with heterologous mucinous elements, representing 38\% (3/8) of cases containing moderately/poorly differentiated SLCT (Figure 3B). Furthermore, they all contained jGCT, but not aGCT, as their female components, representing 38\% (3/8) of cases with SLCT and jGCT components (Figure 3C). Further analysis of the macrodissected jGCT and SLCT components demonstrated that all three cases exhibited the same heterozygous DICERI mutation in both components.

Mutational analysis of FOXL2 at c.402 site (p.C134) by Taqman allelic discrimination PCR assay revealed that all 16 gynandroblastoma had wild-type (WT) FOXL2 (Table 1). In addition, no duplication of the PH domain of $A K T 1$ was identified in any case.

\section{FOXL2 expression in gynandroblastoma by immunohistochemistry}

FOXL2 nuclear expression was present in both the male and female components of all 16 gynandroblastomas. In most cases, staining was diffuse with most of the tumor nuclei being positive. Representative images of FOXL2 immunostaining are shown in Figures 1 and 2.

\section{DISCUSSION}

Gynandroblastoma is a rare primary ovarian tumor with morphological evidence of both male and female sex cord differentiation. Our study analyzed the molecular features of a cohort of 16 ovarian gynandroblastomas. 19\% (3/16) of the cases had DICERI hotspot mutations at the key metal binding sites that are believed to drive oncogenesis in more than half of ovarian SLCTs ${ }^{17}$, 19, 23 , in particular moderately and poorly differentiated neoplasms which often comprise a 
morphological spectrum; in contrast, all well differentiated SLCTs studied so far are DICER1 wild-type ${ }^{19,23}$. Our study demonstrated that $38 \%(3 / 8)$ of gynandroblastomas with a component of moderately/poorly differentiated SLCT had DICER1 mutations, while none of 7 gynandroblastomas with well differentiated SLCT exhibited a mutation, suggesting that some gynandroblastomas may be morphologic variants of SLCT.

All 3 gynandroblastomas in our series with a DICER 1 mutation exhibited a mixture of moderately/poorly differentiated SLCT and jGCT. This is interesting given that areas resembling jGCT may be present in moderately and poorly differentiated SLCTs (personal observations, W.G.M.). de Kock et al. identified DICERI mutations in all 30 moderately and poorly differentiated SLCTs, 2 of which had areas resembling jGCT ${ }^{23}$. Oost et al reported 4 ovarian sex cord-stromal tumours in patients with proven or likely germline mutations in DICER1, 3 of which showed a similar appearance characterized by marked architectural and cytological heterogeneity including sertoliform, jGCT-like and unclassifiable elements ${ }^{24}$. Furthermore, Conlon et al. identified DICER 1 mutations in 2 of 5 gynandroblastomas but did not specifically describe areas resembling jGCT (12). Schultz et al. reported DICERI mutations in all four gynandroblastoma with jGCT in their study but did not provide details of the pathological features ${ }^{25}$. Therefore, these observations suggest that gynandroblastomas with a component of moderately/poorly differentiated SLCT and jGCT are essentially SLCTs with areas showing morphological mimicry of jGCT.

In our study, the DICERI hotspot mutations were demonstrated in both the SLCT and jGCT components in all 3 gynandroblastomas cases associated with the mutation. This supports the concept that the 2 components represent morphological divergence within a single neoplastic lesion. DICERI is an endoribonuclease that controls the production of microRNAs; it remains 
unclear how DICERI mutation drives the development of ovarian SLCT. We have previously reported that DICERI mutation in SLCT was associated with the reduced expression of CYP19A1 (aromatase) that controls estrogen synthesis from testosterone and differentiation of somatic cell lineages in the ovary ${ }^{19,26}$. A recent report also confirmed that DICER1 mutation is associated with an increased testosterone level in patients with ovarian SLCT ${ }^{27}$. Therefore, it is plausible that DICER1 mutation, by decreasing aromatase expression and/or skewing global gene expression, alters the fate of the cell of origin (e.g. granulosa cells of primordial or pre-ovulatory follicles) towards Sertoli-like cells in SLCT and gynandroblastoma, which can then stimulate androgen production in luteinized stromal (Leydig) cells. It is possible that additional genetic or epigenetic events occurring in certain cells during the oncogenic transformation may prevent their cell fate transition into male cell types and become jGCT. Future studies comparing genomic alternations in both SLCT and jGCT components will improve our understanding of the oncogenic process in gynandroblastomas.

In the study by Conlon et al, FOXL2 p.C134W mutations were identified in 2 out of 5 gynandroblastomas and these were mutually exclusive with DICERI mutations (12). The authors did not describe the morphological features of these cases in detail but given that FOXL2 mutation is considered to be a sensitive and specific molecular marker of aGCT it is possible that these neoplasms essentially represent aGCTs with areas mimicking SCT or SLCT. Our current study and that of Oparka et al ${ }^{20}$ did not identify a FOXL2 p.C134W mutation in any gynandroblastomas, although $37.5 \%(6 / 16)$ of the neoplasms in our series displayed an aGCT component. This suggests that the oncogenic process of gynandroblastomas containing an aGCT component is fundamentally different from aGCT, in which the near-universal FOXL2 p.C134W mutation appears to drive tumor development. Supporting this, patients with gynandroblastomas 
with a component of aGCT in the present study were much younger (median age: 24.5 years old) in comparison to pure aGCT (median age: 54 years old) ${ }^{13}$, suggesting that the unique cellular and extracellular microenvironment only present in older patients may be required for FOXL2 mutation-driven transformation.

In one study, in-frame duplications affecting the $\mathrm{PH}$ domain of $A K T 1$ were identified in most jGCTs occurring in girls under 15 years old ${ }^{14}$. In our study, none of the gynandroblastomas exhibited duplication in the $\mathrm{PH}$ domain of $A K T 1$, suggesting that the pathogenesis of gynandroblastomas containing a jGCT component is fundamentally different from pure jGCT.

FOXL2 was expressed in both the male and female components of all 16 gynandroblastomas in our study. Our group has previously examined FOXL2 immunohistochemical expression in a large series of ovarian sex cord-stromal tumours ${ }^{28}$. Positive nuclear staining was present in 95 of $119(80 \%)$ sex cord-stromal tumours, including greater than $95 \%$ of aGCTs, jGCTs, fibromas and sclerosing stromal tumours and 50\% (20/40) of SLCTs, but not in any non-sex cord-stromal tumours tested $(n=368)$, suggesting that FOXL2 is a relatively sensitive and highly specific marker of a sex cord-stromal tumour but is of little or no value in distinguishing between the various neoplasms in this group.

Therefore, our study strongly suggests that gynandroblastomas composed of SLCT and jGCT are morphological variants of SLCT. The molecular basis of gynandroblastomas containing an aGCT component appears to be different from that of pure aGCT, which are usually found in older patients and contain FOXL2 mutations in almost all cases. As the term gynandroblastoma is no longer used in the 2014 WHO Classification of Tumours of the Female Reproductive Organs, we recommend that gynandroblastomas composed of SLCT and jGCT can be classified under SLCT. Identifying pathogenic mutations in SLCT without DICERI mutation may provide tools 
to assess the genomic similarity between gynandroblastomas and SLCT without DICERI

mutations. Future studies of larger cohorts of centrally reviewed cases will be necessary to validate our findings.

\section{ACKNOWLEDGEMENTS}

Y.W., D.G.H. and F.K. designed the study. A.N.K., F.K., J.M., B.T.C., A.L. and J.S. performed experiments. C.B.G., W.G.M. and F.K. provided tumour samples. Y.W. analyzed data and wrote the manuscript. A.N.K., C.B.G., W.G.M., D.G.H. and F.K. edited the manuscript. This work was supported by research funds from the Canadian Institute of Health Research (MOP-130244) and the Terry Fox Research Institute Initiative New Frontiers Program in Cancer (1021). 


\section{References:}

1. Neubecker RD, Breen SL. Gynandroblastoma. A report of five cases, with a discussion of the histogenesis and classification of ovarian tumors. American journal of clinical pathology 1962;38;60-69.

2. Antunes L, Ounnoughene-Piet M, Hennequin V et al. Gynandroblastoma of the testis in an infant: A morphological, immunohistochemical and in-situ hybridization report. Histopathology 2002;40;395-397.

3. Wilberger A, Yang B. Gynandroblastoma with juvenile granulosa cell tumor and concurrent renal cell carcinoma: A case report and review of literature. International journal of surgical pathology 2015;23;393-398.

4. Takeda A, Watanabe K, Hayashi S, Imoto S, Nakamura H. Gynandroblastoma with a juvenile granulosa cell component in an adolescent: Case report and literature review. Journal of pediatric and adolescent gynecology 2017;30;251-255.

5. Tanaka Y, Ueda G, Komeda M, Karita T, Matsumoto K. Granulosa cell tumor of the ovary with sertoli-leydig cell tumor components (gynandroblastoma). Nihon Sanka Fujinka Gakkai Zasshi 1985;37;1919-1923.

6. Yamada Y, Ohmi K, Tsunematu R et al. Gynandroblastoma of the ovary having a typical morphological appearance: A case study. Jpn J Clin Oncol 1991;21;62-68.

7. Chivukula M, Hunt J, Carter G, Kelley J, Patel M, Kanbour-Shakir A. Recurrent gynandroblastoma of ovary-a case report: A molecular and immunohistochemical analysis. Int J Gynecol Pathol 2007;26;30-33.

8. Schultz KA, Schneider DT, Pashankar F, Ross J, Frazier L. Management of ovarian and testicular sex cord-stromal tumors in children and adolescents. Journal of pediatric hematology/oncology 2012;34 Suppl 2;S55-63.

9. Shah SP, Kobel M, Senz J et al. Mutation of foxl2 in granulosa-cell tumors of the ovary. The New England journal of medicine 2009;360;2719-2729.

10. Jamieson S, Butzow R, Andersson $\mathrm{N}$ et al. The foxl2 c134w mutation is characteristic of adult granulosa cell tumors of the ovary. Modern pathology : an official journal of the United States and Canadian Academy of Pathology, Inc 2010;23;1477-1485.

11. D'Angelo E, Mozos A, Nakayama D et al. Prognostic significance of foxl2 mutation and mrna expression in adult and juvenile granulosa cell tumors of the ovary. Modern pathology : an official journal of the United States and Canadian Academy of Pathology, Inc 2011;24;1360-1367.

12. Kommoss S, Gilks CB, Penzel R et al. A current perspective on the pathological assessment of foxl2 in adult-type granulosa cell tumours of the ovary. Histopathology 2014;64;380-388.

13. McConechy MK, Farkkila A, Horlings HM et al. Molecularly defined adult granulosa cell tumor of the ovary: The clinical phenotype. J Natl Cancer Inst 2016;108.

14. Bessiere L, Todeschini AL, Auguste A et al. A hot-spot of in-frame duplications activates the oncoprotein akt1 in juvenile granulosa cell tumors. EBioMedicine 2015;2;421431.

15. Witkowski L, Mattina J, Schonberger S et al. Dicer1 hotspot mutations in nonepithelial gonadal tumours. British journal of cancer 2013;109;2744-2750.

16. Anglesio MS, Wang Y, Yang W et al. Cancer-associated somatic dicer1 hotspot mutations cause defective mirna processing and reverse-strand expression bias to 
predominantly mature $3 p$ strands through loss of $5 p$ strand cleavage. The Journal of pathology 2013;229;400-409.

17. Heravi-Moussavi A, Anglesio MS, Cheng SW et al. Recurrent somatic dicer1 mutations in nonepithelial ovarian cancers. The New England journal of medicine 2012;366;234-242.

18. Conlon N, Schultheis AM, Piscuoglio S et al. A survey of dicer1 hotspot mutations in ovarian and testicular sex cord-stromal tumors. Modern pathology : an official journal of the United States and Canadian Academy of Pathology, Inc 2015;28;1603-1612.

19. Wang Y, Chen J, Yang W et al. The oncogenic roles of dicer1 rnase iiib domain mutations in ovarian sertoli-leydig cell tumors. Neoplasia 2015;17;650-660.

20. Oparka R, Cassidy A, Reilly S, Stenhouse A, McCluggage WG, Herrington CS. The c134w (402 c>g) foxl2 mutation is absent in ovarian gynandroblastoma: Insights into the genesis of an unusual tumour. Histopathology 2012;60;838-842.

21. Kurman RJ CM, Herrington CS, Young RH, eds. 2014 world health organization classification of tumours of the female reproductive organs, 2014.

22. Kommoss S, Anglesio MS, Mackenzie R et al. Foxl2 molecular testing in ovarian neoplasms: Diagnostic approach and procedural guidelines. Modern pathology : an official journal of the United States and Canadian Academy of Pathology, Inc 2013;26;860-867. 23. de Kock L, Terzic T, McCluggage WG et al. Dicer1 mutations are consistently present in moderately and poorly differentiated sertoli-leydig cell tumors. Am J Surg Pathol 2017;41;1178-1187.

24. Oost EE, Charles A, Choong CS et al. Ovarian sex cord-stromal tumors in patients with probable or confirmed germline dicer1 mutations. Int J Gynecol Pathol 2015;34;266274.

25. Schultz KAP, Harris AK, Finch M et al. Dicer1-related sertoli-leydig cell tumor and gynandroblastoma: Clinical and genetic findings from the international ovarian and testicular stromal tumor registry. Gynecol Oncol 2017;147;521-527.

26. Britt KL, Drummond AE, Dyson M et al. The ovarian phenotype of the aromatase knockout (arko) mouse. J Steroid Biochem Mol Biol 2001;79;181-185.

27. Kato N, Kusumi T, Kamataki A, Tsunoda R, Fukase M, Kurose A. Dicer1 hotspot mutations in ovarian sertoli-leydig cell tumors: A potential association with androgenic effects. Hum Pathol 2017;59;41-47.

28. Al-Agha OM, Huwait HF, Chow C et al. Foxl2 is a sensitive and specific marker for sex cord-stromal tumors of the ovary. Am J Surg Pathol 2011;35;484-494. 
Table 1. Clinicopathological features and mutational status of FOXL2, DICER1 and AKT1.

\begin{tabular}{|c|c|c|c|c|c|c|c|}
\hline Case & Age & Male component & $\begin{array}{l}\text { Female } \\
\text { component }\end{array}$ & $\begin{array}{l}\text { Slides } \\
\text { reviewed }\end{array}$ & $\begin{array}{c}\text { DICER1 } \\
\text { RNase IIIb }\end{array}$ & $\begin{array}{l}\text { FOXL2 } \\
\text { p.C134 }\end{array}$ & $\begin{array}{l}\text { AKT1 } \\
\text { (PH domain) }\end{array}$ \\
\hline 1 & 23 & $\begin{array}{l}\text { SLCT (moderately } \\
\text { differentiated) }\end{array}$ & jGCT & 1 & WT & WT & $\begin{array}{l}\text { No } \\
\text { duplication }\end{array}$ \\
\hline 2 & 25 & $\begin{array}{l}\text { SLCT (well } \\
\text { differentiated) }\end{array}$ & $\mathrm{aGCT}$ & 1 & WT & WT & $\begin{array}{l}\text { No } \\
\text { duplication }\end{array}$ \\
\hline 3 & 15 & $\begin{array}{l}\text { SLCT (moderately to } \\
\text { poorly differentiated) }\end{array}$ & jGCT & 2 & $\begin{array}{l}\text { c.5352A->T } \\
\text { (p.E1705V); } \\
\text { c.5731G->A } \\
\text { (p.W1831X) }\end{array}$ & WT & $\begin{array}{l}\text { No } \\
\text { duplication }\end{array}$ \\
\hline 4 & 20 & $\begin{array}{l}\text { SLCT (moderately } \\
\text { differentiated with } \\
\text { heterologous } \\
\text { intestinal-type } \\
\text { mucinous elements) }\end{array}$ & jGCT & 2 & $\begin{array}{l}\text { c.5675G->A } \\
\text { (p.E1813K) }\end{array}$ & WT & $\begin{array}{l}\text { No } \\
\text { duplication }\end{array}$ \\
\hline 5 & 42 & $\begin{array}{l}\text { SLCT (moderately } \\
\text { differentiated) }\end{array}$ & jGCT & 1 & WT & WT & $\begin{array}{l}\text { No } \\
\text { duplication }\end{array}$ \\
\hline 6 & 35 & $\begin{array}{l}\text { SLCT (well } \\
\text { differentiated) }\end{array}$ & $\mathrm{jGCT}$ & 1 & WT & WT & $\begin{array}{l}\text { No } \\
\text { duplication }\end{array}$ \\
\hline 7 & 15 & $\begin{array}{l}\text { SLCT (moderately } \\
\text { differentiated) }\end{array}$ & jGCT & 2 & WT & WT & $\begin{array}{l}\text { No } \\
\text { duplication }\end{array}$ \\
\hline 8 & 20 & $\begin{array}{l}\text { SLCT (well } \\
\text { differentiated) }\end{array}$ & aGCT & 1 & WT & WT & $\begin{array}{l}\text { No } \\
\text { duplication }\end{array}$ \\
\hline 9 & 63 & $\begin{array}{l}\text { SLCT (well } \\
\text { differentiated) and } \\
\text { SCT }\end{array}$ & $\begin{array}{l}\text { aGCT and } \\
\text { micro foci } \\
\text { of jGCT }\end{array}$ & 1 & WT & WT & $\begin{array}{l}\text { No } \\
\text { duplication }\end{array}$ \\
\hline 10 & 80 & SCT & aGCT & 1 & WT & WT & $\begin{array}{l}\text { No } \\
\text { duplication }\end{array}$ \\
\hline 11 & 66 & $\begin{array}{l}\text { SLCT (well } \\
\text { differentiated) }\end{array}$ & jGCT & 1 & WT & WT & $\begin{array}{l}\text { No } \\
\text { duplication }\end{array}$ \\
\hline 12 & 14 & $\begin{array}{l}\text { SLCT (well } \\
\text { differentiated) }\end{array}$ & $\mathrm{jGCT}$ & 1 & WT & WT & $\begin{array}{l}\text { No } \\
\text { duplication }\end{array}$ \\
\hline 13 & 26 & $\begin{array}{l}\text { SLCT (moderately } \\
\text { differentiated) }\end{array}$ & jGCT & 1 & $\begin{array}{l}\text { c.5666G->C } \\
\text { (p.D1810H) }\end{array}$ & WT & $\begin{array}{l}\text { No } \\
\text { duplication }\end{array}$ \\
\hline 14 & 24 & $\begin{array}{l}\text { SLCT (moderately } \\
\text { differentiated) }\end{array}$ & aGCT & 1 & WT & WT & $\begin{array}{l}\text { No } \\
\text { duplication }\end{array}$ \\
\hline 15 & 24 & $\begin{array}{l}\text { SLCT (well } \\
\text { differentiated) }\end{array}$ & aGCT & 1 & WT & WT & $\begin{array}{l}\text { No } \\
\text { duplication }\end{array}$ \\
\hline 16 & 28 & $\begin{array}{l}\text { SLCT (moderately } \\
\text { differentiated) }\end{array}$ & $\mathrm{aGCT}$ & 1 & WT & WT & $\begin{array}{l}\text { No } \\
\text { duplication }\end{array}$ \\
\hline
\end{tabular}

Notes:

1. All cases have at least $10 \%$ of both male and female components, but only a small portion of slides were available for review in each case;

2. SLCT, Sertoli-Leydig cell tumour; SCT, Sertoli cell tumour; aGCT, adult granulosa cell tumour; jGCT, juvenile granulosa cell tumour;

3. PH domain: pleckstrin-homology domain 


\section{Figure legends}

\section{Figure 1. Histology and FOXL2 expression of a gynandroblastoma containing jGCT and}

SLCT components (case 4). (A) and (B), 40x magnification. (C) and (D), 200x magnification of the boxed regions in (A) and (B). Heterologous intestinal-type mucinous glands can be seen in the SLCT component (B and D). (E) and (F), FOXL2 immunohistochemistry of the regions depicted in (C) and (D). FOXL2 is expressed in the immature gonadal stroma of the SLCT component ( $\mathrm{F}$, upper center region) but not in the Leydig cells (lower right) or heterologous mucinous glands.

Figure 2. Histology and FOXL2 expression of a gynandroblastoma containing aGCT and SLCT (case 8). (A) and (B), 40x magnification. (C) and (D), 200x magnification of the boxed regions in (A) and (B). (E) and (F), FOXL2 immunohistochemistry of the regions depicted in (C) and (D). FOXL2 is expressed in the sertoliform tubules of the SLCT component (F) but is negative in the Leydig cells.

Figure 3. Correlation between DICER1 mutational status and clinical features in gynandroblastoma. (A) Association of DICER1 mutation status and the age of gynandroblastoma patients initially diagnosed, $P=0.25$. (B) Association of DICER1 mutation status and the presence of moderately/poorly differentiated SLCT components, $P=0.2$. (C) Association of DICER1 mutational status and the presence of jGCT components, $P=0.21$. 
Figure 1, Wang et al.

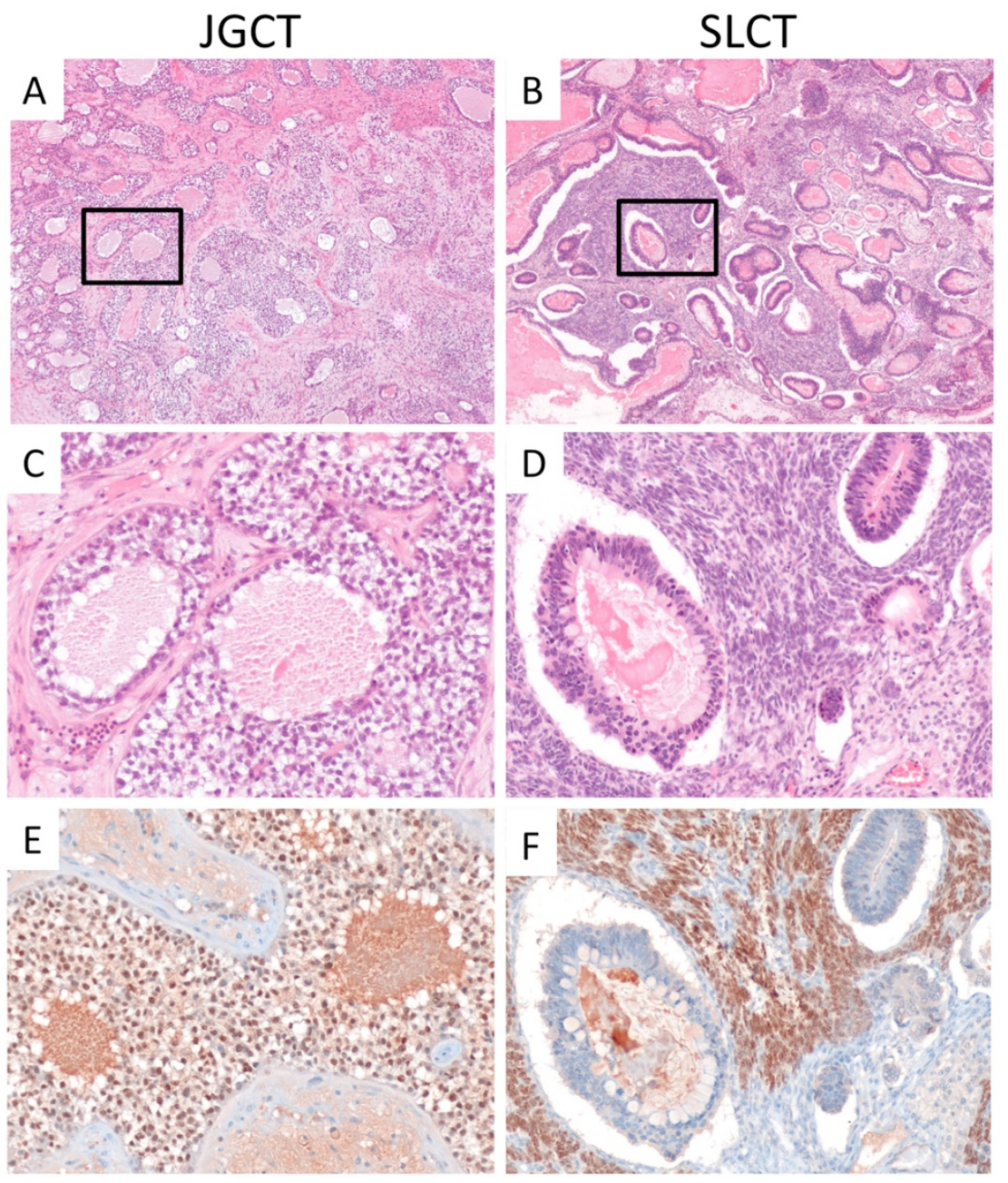


Figure 2, Wang et al.
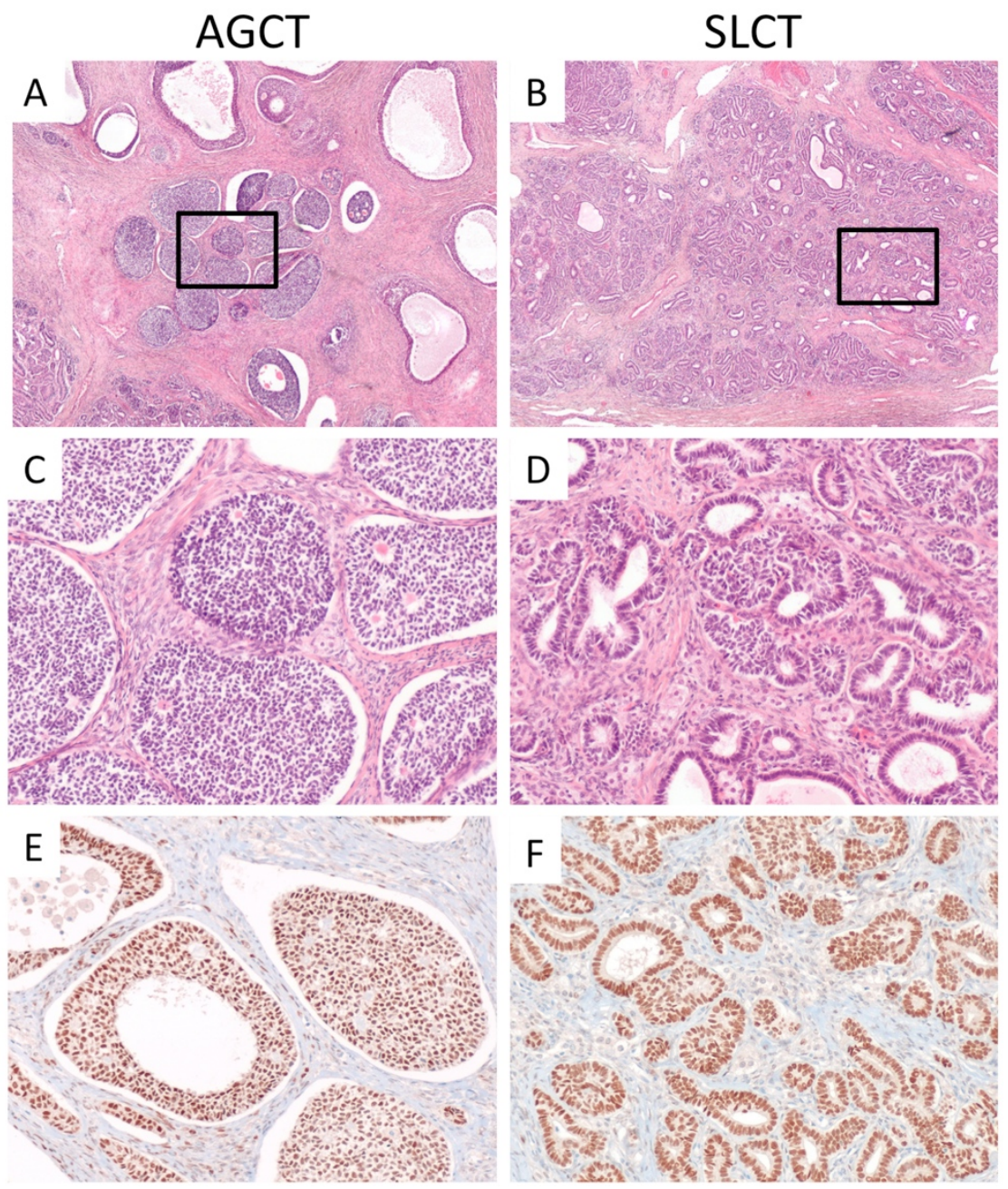
Figure 3, Wang et al.

A

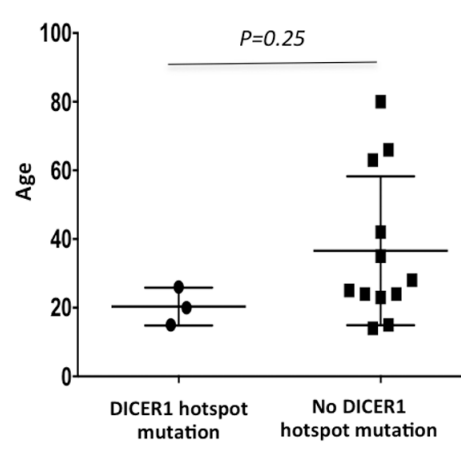

B

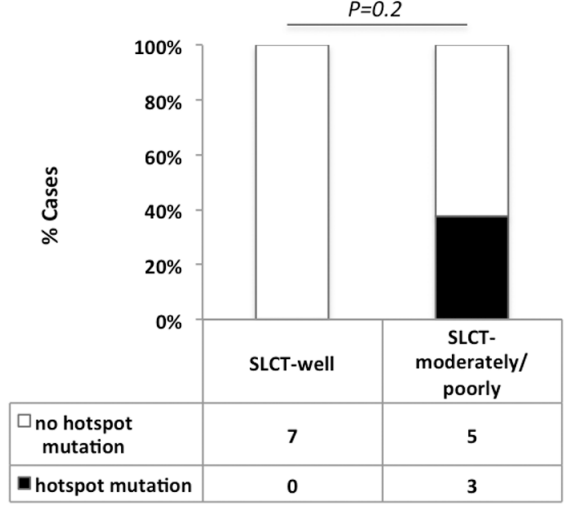

C

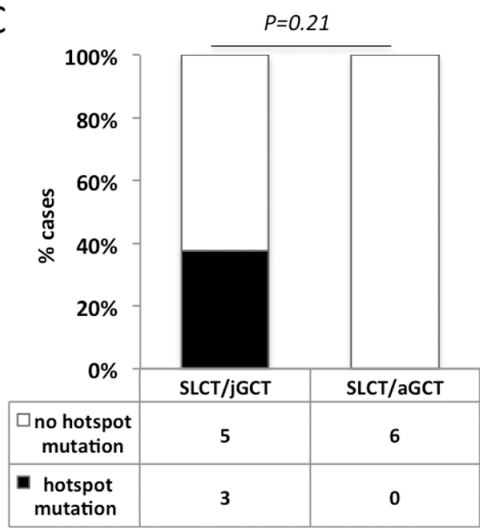

